\title{
Article
}

\section{Existential Communication and Leadership}

\author{
Ashman, Ian and Lawler, John \\ Available at http://clok.uclan.ac.uk/8652/ \\ Ashman, lan and Lawler, John (2008) Existential Communication and \\ Leadership. Leadership, 4 (3). pp. 253-269. ISSN 1742-7150
}

It is advisable to refer to the publisher's version if you intend to cite from the work. http://dx.doi.org/10.1177/1742715008092361

For more information about UCLan's research in this area go to http://www.uclan.ac.uk/researchgroups/ and search for < name of research Group>.

For information about Research generally at UCLan please go to http://www.uclan.ac.uk/research/

All outputs in CLoK are protected by Intellectual Property Rights law, including Copyright law. Copyright, IPR and Moral Rights for the works on this site are retained by the individual authors and/or other copyright owners. Terms and conditions for use of this material are defined in the policies page.

\section{CLoK}

Central Lancashire online Knowledge www.clok.uclan.ac.uk

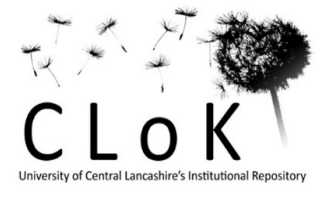




\title{
Existential Communication and Leadership
}

Revised and resubmitted to the 'Communication and Leadership' special edition of Leadership

$\underline{\text { Author Contact Details: }}$

Dr. Ian Ashman

Department of Strategy and Innovation

University of Central Lancashire

Preston, PR1 2HE

Tel: (01772) 894782

iashman@uclan.ac.uk

and

\author{
Dr. John Lawler \\ School of Health Studies \\ University of Bradford \\ 25 Trinity Road \\ Bradford, BD5 0BB \\ Tel: (01274) 236393 \\ j.lawler@bradford.ac.uk
}

\begin{abstract}
The aim of this paper is to introduce and explain a number of important existentialist philosophers and concepts that we believe can contribute to a critical approach to leadership theory. Emphasis is placed on understanding the nature of communication from an existentialist perspective and so Jaspers' conceptualisation of existential communication is introduced along with important related concepts that may be regarded as important facets of leader communication including Being-in-the-world, the Other, intersubjectivity, dialogue and indirect communication. Particular attention is paid to Buber's' ideas on communication as relationship and dialogue. Throughout, reference is made to contemporary and, what is often regarded as, orthodox thinking regarding the centrality of communication to leadership practice as a means by which to highlight the salience of an existentialist analysis.
\end{abstract}

Keywords Buber; dialogue; existentialism; indirect communication; relationship 


\title{
Existential Communication and Leadership
}

\begin{abstract}
The aim of this paper is to introduce and explain a number of important existentialist philosophers and concepts that we believe can contribute to a critical approach to leadership theory. Emphasis is placed on understanding the nature of communication from an existentialist perspective and so Jaspers' conceptualisation of existential communication is introduced along with important related concepts that may be regarded as important facets of leader communication including Being-in-the-world, the Other, intersubjectivity, dialogue and indirect communication. Particular attention is paid to Buber's' ideas on communication as relationship and dialogue. Throughout, reference is made to contemporary and, what is often regarded as, orthodox thinking regarding the centrality of communication to leadership practice as a means by which to highlight the salience of an existentialist analysis.
\end{abstract}

Keywords Buber; dialogue; existentialism; indirect communication; relationship

\section{Introduction}

This paper sets out to introduce and explore a number of existentialist concepts and principles by taking account of contemporary leadership theory and practice. The intention is to show how existentialist philosophy can contribute to a critical approach that may be used in the examination of the interdependency between leadership and communication. Within the leadership literature, communication is often regarded as an essential aspect of the leadership relationship or as a prime leadership skill. In this paper we suggest that this might be reversed and that leadership might be considered as an aspect or subset of communication.

It might be argued that leadership, however defined (accepting the plethora of definitions as noted by, for example, Stogdill, 1973), and when all is said and done, is communication. In other words, leadership is no more than one aspect of communication although, of course, communication need not involve leadership. Perhaps, as we argue here, it may be the case that communication as it is understood from an existentialist perspective precludes the notion of a relationship that invokes 'leader' and 'follower'. Much is traditionally assumed, within and beyond the leadership literature, about communication and its purpose. In connection with leadership, it is often regarded instrumentally, that is, effective communication is necessary so that other things can occur: effective performance, motivation, inspiration, understanding the vision and so on. This is exemplified in approaches which seek to transmit the leader's vision to others in the organisation (such as, Conger and Kanungo, 1998) and studies which explore the use of vision and mission statements (such as, Rigby, 2001; The Leadership Trust, 2002). Even where some of the complexities and dynamics of leadership are recognised, its purpose is still seen instrumentally. For instance, Kakabadse (1991) notes that leadership communication is two-sided but rather than being seen as relational, is deemed to be distinguished as communication which provides either direction or example. This twofold (though one-directional) communication is identified by others: 
"Leaders communicate as a means of motivating followers to act... the essential behavior or skill is communicating: what is communicated generally is seen as having to do with a vision of the organization's future" (Antonakis et al 2004, 190-1).

Arguably, such a restrictive view ignores other aspects of communication and other potentialities, within leader relations.

Taking account of the intimate connection between leadership and communication it is remarkable that the concept of communication is taken so much for granted in the literature on leadership. The conventional view appears to be that communication is a process that involves no more than the transmission and reception of information or that such transmission in itself results in positive outcomes such as experiencing involvement or commitment or becoming 'enlisted' (Kouzes and Posner, 1987). Thus, problems of leadership that are often seen as occurring as a consequence of faulty communication can be corrected by simply opening up channels and reiterating or clarifying the content of the message (Fisher, 1974). Communicating, therefore, becomes a competence or skill to be acquired by the leader as a means of overcoming the followers' inability to comprehend their role in the organisational scheme of things. Frequently the solution to organisational difficulties is to communicate more or communicate better, with no sense that perhaps the root cause of the problem is a failure to grasp what communication truly entails and thus overlook the argument succinctly voiced by Watzlawick et al (1967), that one cannot not communicate.

We argue that the orthodox view of communication, presented or assumed in the majority of the literature on leadership is very narrow and potentially misleading (for example, ideas including leaders 'managing the attention' of others (Bennis and Nanus, 1985) or inspiring others through articulation of the vision (Bass and Avolio, 1994)). The typical view is that communication in organisations amounts to a series of transactions or conversations between various individuals (Littlejohn \& Foss, 2005) with implied and prescribed active and passive roles. We adopt, as we have in the past, an existentialist position that views communication as being about encounters and relationships as much as it is about the transmission of information (for a broader discussion of existentialist philosophy and its relevance to leadership theory and practice see - names removed for reviewing purposes). Collinson (2005) has argued recently that a growing interest in the notion of 'leadership distance' reflects an appreciation that leadership in organisations is as concerned with leader/follower relations as it is with styles and traits. We hope that this paper reinforces that recognition and develops some of the thinking behind it.

It is not possible to convey the entirety of existentialist thinking on the subject of communication in the space that we have here. Likewise, it is difficult to express the centrality of communication (as theory, practice and praxis) to existentialist philosophy. Consequently, our aim is to introduce what we consider to be the most significant existentialist philosophers and concepts that will enable us to reconsider the part played by communication in the development and application of leadership theory. It is not our intention to dwell upon the many, often subtle, differences that certainly exist among and between these various philosophers and their philosophies, but instead to attempt a synthesis of their ideas into what we hope is a coherent explanation of broad themes. 


\section{Existential Communication}

Our first task is to attempt to explain the concept of existential communication, but we are confronted immediately with a seemingly insurmountable paradox, because the idea itself is considered to be incommunicable. Paradoxical, perhaps, but there is not a hint of irony - after all, how can we understand communication when the ability to comprehend depends upon communicating that understanding? Hence, the writings of many, if not most, existentialist philosophers are intentionally ambiguous because they grasped the futility of attempting to pinpoint the meaning of the medium through which the meaning is being conveyed. The aphoristic, often rhetorical, style of philosophers normally included in the existentialist tradition, such as, Kierkegaard, Nietzsche and Buber, contains the recognition that, to quote Marshall McLuhan's often misunderstood phrase- the medium is the message (Federman, 2004).

The point is made by Karl Jaspers who, in affirming Kierkegaard's misgiving towards the Hegelian certainty of the pre-eminence of scientific knowledge, suggests that learned professors (of science):

"Do not experience the maturity of that critical point where everything turns upside down, where one understands more and more that there is something which one cannot understand." (Jaspers, 1997: 25-6)

Indeed, Jaspers' philosophy of Existenz offers little that is wholly tangible demanding the interpretation of an interpretation, which reaches no end - but is intended to open up the possibility of genuine personal insight. According to Jaspers any totalising system that sets out to make the whole truth communicable is deluded; the truth is always partial (1997: 26).

It is Jaspers' explanation of existential communication that we shall begin with for he appears to have coined the term first. Jaspers' single most comprehensive exposition on communication is his lecture Truth and Communicability, published with four related lectures in the book Reason and Existenz (Jaspers, 1997 first published in 1935). However, consideration of the fundamental importance of communication is found right across his oeuvre (for instance Jaspers, 1954, 1961 and 1969/1971). Jaspers' thinking on communication is bound tightly with the premise that we have just mentioned; that there are some aspects of human existence that are unknowable an idea that he encapsulates in the concept termed Existenz.

Before he explains Existenz Jaspers identifies three other modes of being (1997: 549). The first is empirical existence, which is our immanent relationship with the world; what we might consider to be the domain of the empirical sciences, of nature, of externality, and of our perceived reality. The second mode is consciousness; a notion representative of our inner world of thinking that supplies meaning to empirical existence. The third mode is spirit; associated with such things as personal ideology, creativity and religious belief. The parallels with Kierkegaard's (1949) three spheres of existence (the aesthetic; the ethical; and the religious) are clearly apparent, although unlike Kierkegaard, Jaspers does not privilege any one mode over 
and above the others. Jaspers' modes of being function simultaneously and complement one another, although importantly, he insists they can be surpassed.

Thus, Existenz is a fourth dimension that occurs beyond the three other modes of being. Existenz exceeds objective existence into the endless realm of undetermined freedom that defines all existentialist philosophy. It is the communication of truth that draws the individual into the realisation of Existenz; an apprehension that is accompanied by certain moral attitudes such as, courage, patience, dignity, integrity, fidelity, solidarity and, in particular, responsibility (Salamun, 1999a: 151). Of course, by truth Jaspers is referring to something far more than the factual correctness that we usually understand 'truth' to mean - that conventional meaning is representative only of the truth of the empirical mode of being. Truth signifies much more in the other modes of being.

The notion of multiple truth or truths resonates with other critical management approaches (see, for example, McKelvey, 2002). The particular contribution of existential thinking here is the combination of truth in relation to different modes of being. Again, as with the modes of being, there is no sense that one conception of truth is more important than the others. All are vital and must be present together for the whole or real truth to be reached. This contrasts with critical approaches which argue that there can be no stable truth (Linstead, 1993) or that truth is 'multiple (and) idiosyncratic' (Macguire et al. 2006: 196) However, in common with critical approaches, truth is not seen as one-dimensional. In this context it can be seen as having a number of facets.

According to Grieder (1999: 473), Jaspers' notion of multiple truths occurs across five echelons that roughly overlay his modes of being. The first conception of truth is pragmatic truth, which involves the usefulness of a belief or an opinion. The second is the truth of consciousness-in-general, a notion that approximates to the conventional meaning referred to above; in other words, the truth of science. The third, the truth of spirit, is founded in the conviction that lies behind a belief or idea, and the desire to pursue it. The fourth truth is the truth of existence, which corresponds to an awareness of what it means to be oneself, something akin to authenticity, and finally the truth of transcendence. This last notion of truth, as the name implies, concerns moving beyond the realm of objective existence into Existenz and is perhaps best illustrated in Jasper's words that emphasise the subjectivity of truth.

"Truth does not lie in something already known, or something finally knowable, or in an absolute, but rather in what arises and comes to pass. Here there is only a relative and changing truth, for empirical existence itself changes.” (1997: 81)

In some respects this has echoes of notions of the 'management of meaning' in leadership relations (Smircich and Morgan, 1982), but unlike that approach, Jaspers' existentialist perspective recognises the potential for truth in and through existence, rather than the restriction or manipulation that the management of truth or meaning often implies. 
According to Jaspers, the truth of Existenz can only be apprehended through two conditions. First, the experience of what Jaspers refers to as boundary situations (generally, emotional events such as facing death, experiencing pain or things involving fear, guilt, anguish, despair and so on), what might be called intrapersonal realisation, and second, via existential communication, what we might consider to be interpersonal realisation. Boundary situations are perhaps rare, though not unheard of, when leadership is experienced during day to day organisational life and so existential communication presents a more likely vehicle to move towards a truth that reveals the value of relationships and existential freedom.

There are already indications here of how such an approach might deepen our understanding of communication in leadership. At one level, this perspective leads us to challenge generalised prescriptions of leadership, such as charismatic or transformational approaches. It indicates that leadership skills often associated with communication may be considered superficial and, by contrast, it emphasises the need for leaders to acknowledge and engage with the depth of relationship and the dynamic nature of communication. We go on to explore this in our later discussion of dialogue.

As we mentioned earlier, existential communication is addressed throughout Jaspers' writing, so it is helpful that Salamun (1999b: 398-9) has defined the fundamental features of the idea by identifying the 'moral attitudes' that are the necessary preconditions of existential communication (morality and ethics being the subject of considerable existentialist attention - see, for instance, names removed for reviewing purposes). Salamun outlines each as follows:

1. The subject of, or participant in, communication is not treated as a means to the individual's own existential ends. The intention is not solely selfrealisation, but to help the partner to realise his or her own Existenz.

2. An open mind is essential, along with a candour that may well leave the individual feeling vulnerable, but will reveal the possibility to change taken for granted modus operandi.

3. There must be a willingness to accept the communication partner as an equal, regardless of their status.

4. There exists an intellectual integrity and honesty that enables the individual to recognise and criticise one's own failings with the same force as one does others.

5. Last, there must be a readiness and ability to withstand the solitude that may be the consequence of the self-realisation of existential communication and, therefore, not to seek to avoid loneliness at any price.

Once again, in this list we discover both challenges to, and reinforcements of, leadership modes of thinking. For instance, there is a challenge to the natural assumed 'power' of the individual leader whilst, at the same time, a reinforcement of the importance of more than superficial engagement with staff. Each of these issues or 'attitudes' is important in its own right, and merits more discussion than space allows, however, it should be noted that all of the above attitudes contrast with the stereotyped image of the strong, independent leader. For instance, the idea of welcoming experiences of vulnerability, equality, loneliness and openness to personal change rarely features in conventional representations of leaders. 
From the above points, a basic grasp of existential communication becomes possible, but we want to illuminate further the concept by exploring the core constructs that underpin it, whilst at the same time showing that the broad principles are important across the whole of existentialist philosophy and not just in the work of Jaspers. Specifically, we will discuss the primacy of Being-in-the-world (the lifeworld), the emphasis on 'the Other' in existentialism, the role of intersubjectivity in human relations, the importance of dialogue, and last, the paradox that is indirect communication - a challenge to the received wisdom that a message must be unambiguous to be of value.

\section{Being-in-the-world}

Being-in-the-world may be considered the sine qua non of all existentialist philosophy. This concept is central to the thinking of, for example, important existentialists, such as, Husserl and Heidegger and also other critical theorists including Gadamer and Habermas. A definition of Being-in-the-world provided by Polt (1999: 46) is helpfully concise:

"This term indicates that we are essentially involved in a context we have a place in a meaningful whole where we deal with other things and people. The particular content of this context will vary from person to person, and from culture to culture. But it can be said ... that our relation to the world is not disinterested - it is active engagement. We are not, and never can be, radically detached from the world.”

A particular concern regarding leadership research is the tendency to ignore the situatedness of organisational leadership in favour of a detached approach which emphasises scientific method over and above an engagement with day to day experiences occurring in specific contexts. As Pivcevic puts it:

"Bewilderment about the meaning of science is due to science being divorced from its historical human context ... modern science although helping us to understand nature better and to dominate it more successfully, tends to conceal from us the world as our world." (1970: 76)

For the existentialist people are fundamentally Beings-in-the-world, experiencing the world's immediacy and practicality. Ultimately they are always active participants in the events of the world around them; even should they desire not to be. Likewise, they cannot transcend the world in an attempt to treat it dispassionately (that is, objectively) in a manner that scientific enquiry insists is possible. To attempt to transcend existence may be considered inauthentic and ultimately futile. Thus, Beingin-the-world is of particular importance when considering relationships that develop between leaders and those that they are expected to lead. 'Followers' cannot be viewed as homogeneous because every relationship is, like every individual, unique and, therefore, different. Whilst there are some relational models of leadership such Leader-Member Exchange (Graen and Uhl-Bien, 1995) these still do not account for specific individual relations, nor for the unique contexts within which they operate. 
Being-in-the-world is a vital concept in the analysis of leadership because it focuses attention on the fact that the actions of leaders are always situated and grounded in a day-to-day milieu. Universal models of leadership, as noted above, imply transcendence: certain identified principles or characteristics are seen to apply regardless of context but transcendence does not account for the unique experiences of individual lifeworlds. Leadership seen as being-in-the-world, allows us to take into account such individual contexts. Leadership is seen, using this inter-subjective view, as alive and uncertain - leaders are inter-personally engaged with the world. This implies leadership as a dynamic process rather than a linear relationship - leaders (active) and followers (passive). Moreover, it implies that this dynamic process is self-creating, self-realising: engagement with the world develops and explores the potential both of individuals and of the relationship/process itself. The prime implication for leadership practice is not how leaders might engage followers but how all those involved in the process, including the individual leader, can themselves become engaged.

An important aspect of the being-in-the-world relationship process is the freedom to enter different social relationships and the choice that this in turn implies. In much of the leadership literature the enduring relationship between leader and follower is taken as given. Introducing choice in this context means those involved have the freedom to engage (or not) in leader relations. Such a view makes problematic concepts such as 'empowerment' in leadership, in other words, who is the leader to grant freedom or power to the others? Hence, assigning leadership responsibilities to one person does not guarantee this will be accepted by others and similarly leadership presence is no guarantee of effectiveness. This important premise leads us on to consider the role of others in existentialism and in existential communication.

\section{The Other (other people)}

The notion of alterity, along with the place and part of consciousnesses other than our own, has always been a central problematic in existentialist thinking. The reality of other minds must be accepted but for a philosophy that emphasises the undetermined individual the question is what part do others play in one's existence? Can the Other be apprehended as an object, like any other object, or are they special in some way? The corollary, of course, concerns an understanding of how one is seen by others. In the fields of communication theory and leadership theory it is vital to comprehend the role of the Other because communication and leadership are meaningful only where interaction occurs between people.

Frequently there is a strong temptation to objectify other people in the workplace in the same way that a piece of equipment is objectified - they become something 'for me to use to meet my own ends' and such a perception is often found in the treatment of 'followers' by leaders. Across all existentialist philosophy, however, there is a recognition that, despite every individual's desire to objectify other human beings, they cannot because the Other is quite unlike a tool or piece of technology, another person possesses a consciousness like their's. In other words, the Other has his or her own free will that encroaches on the freedom of that individual. The leader may desire or demand that subordinates follow, but ultimately, whether they follow or not 
is always dependent on the personal choice of each worker, regardless of coercion or their apparent inferior position.

While the subjectivity of the Other is accepted by all existentialist thinkers the nature of the influence that the Other has on an individual's consciousness is contested. For instance, Nietzsche, Sartre and Heidegger are all somewhat pessimistic about the effect others have on an individual character, whereas, Jaspers and Buber are unequivocally positive. Nietzsche saw specifically Christian society as a force preventing the realisation of the Übermensch; Heidegger viewed others as a cultural morass into which one falls, tending towards the lowest common denominator, thus undermining the authenticity of the individual; and for Sartre the Being-for-others represents a constant source of psychological anxiety - as he put it in his play Huis Clos, 'hell is other people'. On the other hand, for Jaspers, as we saw earlier, and for Buber, as we explain later, the Other is crucial in enabling us to be all that we can. Again we can see how the concept of empowerment is misplaced: we and the other are mutually engaged. This again runs counter to the notion that a relatively passive workforce is waiting to be engaged by an inspirational or visionary leader who treats them as instrumental in that engagement is seen as a means of greater organisational effectiveness (Watson Wyatt 2006/7)

\section{Intersubjectivity}

It is not appropriate to discuss existential communication without mentioning briefly the notion of intersubjectivity. It is a widely discussed concept so we will provide only brief coverage (those wanting detailed explanation might consult Crossley (1996), for instance). Intersubjectivity, as the term indicates, is central to any philosophy where either idealism or subjectivity is an important element. Intersubjectivity represents the overcoming of pure objectivity. It signifies interpersonal engagement, through any number of means of communication that

approximates towards objectivity and it enables shared experience and an understanding between parties.

To place intersubjectivity in the context of the preceding discussion we might say that it is the thing that creates the possibility of knowing the Other and then locating one's self and them within our lifeworld. The consequence of all this is a "world held in common" as Sokolowski (2000: 152) describes things. Intersubjectivity is used as a catch all phrase to encompass notions that we are all very familiar with; such as, sympathy, empathy, understanding, connectedness, reciprocity, acceptance, resonance - the list could go on. Put simply it is what makes it possible for a subject to appreciate the Other's situation. For instance, when someone says they have a 'splitting headache' we cannot know their pain, but by referring to our own experience and intuition, and by engaging with intersubjectivity, we are able to grasp (usually quite accurately) their sensation. In Buber's terms we remain ourselves but understand the other (Buber, 2002). It is not difficult to see how the notion of intersubjectivity can inform the appraisal of the rapport between leaders and followers. This provides a contrast though with other notions of leader-follower relations such as LMX (Graen and Uhl-Bien, 1995) in that intersubjectivity does not simply allow an awareness of the other but presents the foundation for creating new consciousness, new states of being through and in the communication process. The 
results of effective communication thus might not be demonstrated in e.g. improved results but in changes in both parties.

It is important to recognise that leaders and followers need to be aware of their own intersubjectivity in order to function properly. Indeed if we take an interpretation of leadership as an emergent, distributive phenomenon (for example, Gronn, 2000) the concept of intersubjectivity becomes ever more crucial to an understanding of leadership communication. It is not, of course, something that can be trained into an individual (although it can be learned - see our discussion later on indirect communication), but instead requires an opening up to what Martin Buber refers to as Dialogue.

\section{Dialogue}

Despite it being Jaspers who defined existential communication it is Martin Buber's treatise I and Thou (1958 first published 1923) that is the most frequently cited existentialist work in the field of communication theory. On the face of it this brief text seems to have little to say about communication in its conventional sense, however, because a central theme concerns how the individual can establish a direct relationship with God by understanding human experience through a communicative dialogue with other beings (Smith, 1958: 5), there is a clear relevance.

It is customary to point out that $I$ and Thou is as much, if not more, a work of theology as it is a work of philosophy. However, it is accepted generally that Buber's ideas about dialogic communication can be appreciated quite readily even when separated from its religious context. For instance, Cissna and Anderson suggest that $I$ and Thou should be read as a text that:

"Poetically described the option of humane dialogue in a technologized and often objectified society.” (2002: xv)

Buber's writing may be considered poetic because his style is often aphoristic and perhaps deliberately opaque. Moreover, this notion of the poetic can also be seen beyond that of a style of writing. In her discussions of dialogue, Cunliffe (2002) - in the interpretive though not existential tradition - refers to the poetics of dialogue. In this usage it refers to the capacity to inspire or to move someone, that is, the affective ability of dialogue. Buber seems to have adopted an indirect approach to communication that is typical of many existentialist thinkers and it is a matter that we shall return to shortly. Likewise, Buber's concern regarding the divide between subjective human experience and the objectification of society is also shared with many existentialists. The concept of dialogue is, of course, central to our analysis of leadership and communication, but first we must outline some of Buber's basic principles in order to establish the possibilities for their application.

Buber begins by emphasising the twofold attitude of man and, what he calls, the primary words.

"The one primary word is the combination I-Thou.

The other primary word is the combination I-It.” (Buber, 1958: 15) 
Here, in another existentialist predilection, compound terms become a single word. These primary words represent two fundamental modes of existence. The I-It establishes the individual in an objectified relationship with the world. The $I$ of the $I$ It is an observer of the world, where the objects (Its) in the world exist principally for the benefit of the individual - to be explored, manipulated and used - or in a single word that we touched upon earlier; objectified. From Buber's perspective the I-It represents an impoverished mode of existence and has clear parallels with concepts introduced by other existentialists, such as Kierkegaard's Aesthetic Sphere, Sartre's bad faith, and Heidegger's theyness. The I who stands in an I-It connection with the world is not encountering the world as Being-in-the-world and so, therefore, has a diminished understanding others and their own state of being. The consequences of existing only in the I-It mode are very real - resulting in a sense of alienation and a frequent overbearing feeling of existential angst.

The $I$ of the $I-T h o u^{1}$ experiences a quite different engagement with the world. In this type of relationship the individual encounters existence as a subject among other subjects. The I-It necessarily involves a distance between subject and object, whereas the I-Thou requires interaction in close proximity. Gordon (1999: 59) encapsulates Buber's meaning with a particular sensitivity.

"Speaking the I-Thou can establish the world of relation between the I and the human partner, natural creatures, or spiritual beings such as works of art or God. A person who relates dialogically may, in a moment of grace, encounter the Other as Thou. The highest human challenge is to be guided in one's life by I-Thou encounters and to realize in the everyday what one has learned from such encounters.”

Thus, as we mentioned earlier, for Buber the individual is in large part developed by communicating with other people when guided by the I-Thou attitude. He distinguishes between the dominant mode of communication, which involves simply experiencing others in the I-It attitude, and encounters with others in the I-Thou mode. Experience is inevitable as we attempt to grasp the world around us, but when adopting the I-It attitude in the presence of others we impoverish them. We argue that leader - follower relationships are largely based upon I-It experiences and rarely upon I-Thou encounters.

In Between Man and Man (Buber, 2002 originally published 1947) Buber identifies three types of dialogue:

"Genuine dialogue ...where each of the participants really has in mind the other or others in their present and particular being and turns to them with the intention of establishing a living mutual relation between himself and them. There is technical dialogue, which is prompted solely by the need of objective understanding. And there is monologue disguised as dialogue in which two or more men, meeting in space, speak each within himself in

\footnotetext{
${ }^{1}$ We will persevere with Ronald Gregor Smith's rather formal translation (no doubt influenced by his strong religiosity) of Buber's Ich-Du as I-Thou, even though I-You is a more accurate and comfortable translation for the contemporary reader.
} 
strangely tortuous and circuitous ways and yet imagine they have escaped the torment of being thrown back on their own resources.”

(Buber, 2002: 22)

Buber talks of seeing 'the Other' in different ways. The observer identifies certain characteristics of the other and categorises that person in one or several ways. The onlooker sees the other in a more rounded, individual and contextualised way. Both these roles are detached from the other - they both view the other in some objective way. He argues though that there is an entirely different perspective, when the other 'says something' to a person which cannot be grasped in an objective way. (This can also apply in relation to inanimate objects, for example mountain scenery which has the power to affect one's emotions). It is in this relationship where meaningful dialogue occurs, when someone becomes 'aware' of the possibilities.

According to Arnett and Arneson (1999 p128), interpreting Between Man and Man, the critical incidences of personal development, of existential growth, come in the between; that is, between person and person. They claim that "life is 'best' lived between persons" (1999: 129). It is around this "common center" that genuine dialogue takes place.

From Buber's position, only through dialogue can one 'experience the other side'; that is, only through 'inclusion' of the other. He argues though that this is different from empathy, which implies an abandonment of one's own position. Dialogue involves maintaining one's own existential position and accepting that of the other. The ontological reality of the 'between' (Buber, 2002: xiv) is emphasised as we note above. Dialogue and communication are not dimensions of the self, rather they act:

"as the existential and ontological reality in which the self comes into being and through which it fulfils and authenticates itself." (Buber, 2002: xv)

The question, of course, from our point of view is whether it is possible for dialogue to occur between leader and follower. The remark earlier attributed to Jaspers - that existential communication is possible, regardless of relative status, so long as the communication partners accept each other as equals - suggests that it is conceivable. However, the corollary of that question is another; is it ever possible for a leader and follower to accept each other as equals?

Buber's response to the latter question appears to be that such an acceptance is unlikely. Evidence for saying this is found in a discussion that took place in 1957 between Buber and the American humanist psychologist (and psychiatrist) Carl Rogers (Buber 1998: 156-174). Rogers claimed that on occasions he felt that he was able to engage his patients in a genuine dialogue that approximates towards the $I$ Thou relationship, which he portrays in the following words.

"I feel that when I am being effective as a therapist, I enter the relationship as a subjective person, not as a scrutinizer, not as a scientist. I feel, too, that when I am most effective, then somehow I am relatively whole in that relationship, or the word that has 
meaning to me is 'transparent' [...] There is nothing hidden. Then I think, too, that in such a relationship I feel a real willingness for the other person to be what he is. I call that 'acceptance' [...] I sense with a good deal of clarity the way his experience seems to him [...] Then, if in addition to those things on my part, my client or the person with whom I'm working is able to sense something of those attitudes in me, then it seems to me that there is a real, experiential meeting of persons, in which each of us is changed." (Buber, 1998: 159-160)

Despite Roger's conviction Buber is sceptical because, for want of a better expression, the imbalance of the healer/patient relationship simply cannot be dissolved or suspended. Buber remarks:

"You [Rogers] have necessarily another attitude to the situation than he [the patient] has. You are able to do something that he is not able. You are not equals and cannot be.” (Buber, 1998: 162)

We can draw parallels here between the healer/patient relationship and the leader/follower relationship. Within an organisational context it is the power imbalance that, perhaps, cannot be dissolved in the leader/follower relationship. Buber even suggests that it is because of Rogers' position that he is able to indulge in the feeling that he wills the Other to be what he is, but that feeling is not going to be reciprocated, that is, the patient has no interest in willing the therapist to be what he is - the patient just wants help for their own sake. However, in Between Man and Man, a work that predates the Rogers discussion by a decade, Buber seems to acknowledge that it is possible to accept each other as equals in that we can accept each other as humans allowing for individual difference including organisational position.

Buber's equivocation notwithstanding, it is clear the challenge for those researching leadership is to search for incidents where such acceptance is manifest and then to look for the consequences. Collinson (2005: 237) highlights the complexity associated with interpreting the functioning of charismatic or transformational leadership when acknowledging the dilemma of psychological distancing. Drawing on Katz and Kahn's (1978) work he points out the potential catch-22 for leaders who want to maintain psychological distance from followers in order to preserve a 'magical' image and to hide fallibilities, whilst at the same time needing psychological closeness to enable them to establish a sense of shared identity and trust. Such mind games do not auger well for the nurturing of existential communication. Nonetheless, just one occurrence of the sort of leader/follower acceptance Buber describes will enlighten us as to the possibilities of genuine dialogue between leader and follower; unfortunately, our next discussion point suggests that the search is not likely to be easy.

\section{Indirect Communication}

It seems a truism to say that any form of interpersonal communication should be as direct and unambiguous as possible, and yet, as we have already mentioned, almost the entirety of existential doctrine appears to be vague and often obtuse. This is quite 
deliberate on the part of existentialist philosophers and this paradoxical element of existential communication deserves comment.

Two reasons explain the paradox. First, there is the quandary of communicating a concept through the medium of the concept itself - the problem of communicating the incommunicable. For instance, Buber believed that an understanding of the I-Thou would develop not from a detailed analysis of his work, but only from an exploration of the reader's own selfhood. Hence, Buber's style of writing is aphoristic, poetic even, and littered with personal vignettes intended to guide the reader to look inwards toward their own existence. Jaspers shares a similar approach, if slightly less florid, reaching out towards Existenz.

The second reason is reflective of the view that communicating by indirect use of language (the pre-eminent vehicle for existentialists) opens up possibilities and acknowledges the freedom of the Other (the reader most usually). For Nietzsche it was about mistrust and playfulness, for Kierkegaard it was about learning and edification.

Kierkegaard ruminates at some length on the possibilities of communication and he had a particular interest in the use of irony, which he employed to great effect in his own writing. His aim was not to instruct the reader, but to emancipate them; to put them in touch with their own subjectivity and to emphasize the freedom through which to explore their own faith and sense of Being. In his Concluding Unscientific Postscript, Kierkegaard explains that:

"Indirect communication makes communicating an art in a sense different from what one ordinarily assumes it to be in supposing that the communicator has to present the communication to a knower, so that he can judge it, or to a nonknower, so that he can acquire something to know. But no one cares about the next thing, the very thing that makes communication so difficult dialectically: that the receiver is an existing person, and that this is the essential. [..S]uch is the relation between an existing person and an existing person when the communication pertains to the truth as existenceinwardness.” (Kierkegaard 1992 p277)

There is a clear connection to the question of intersubjectivity here. In short, Kierkegaard's argument is that ability and understanding cannot be given to the Other, it can be communicated only indirectly so that the Other can discover it for him or herself (Weston, 1994 p141). This interpretation of the communicative relationship has important ramifications for our comprehension of the interaction between leaders and 'followers'. It suggests that communication between leader and 'follower' is likely to fail where it is simply directive and the subordinate sees themselves as passive. Thus, the preferable relationship is one where all parties are equally active in the pursuit of understanding, but that runs counter to the normally prescribed roles and power relationship between leader and follower.

It is interesting to contrast the use of indirect communication in existentialist writing with the use of the same sort of technique by leaders in industry and politics. For 
instance, some elements of the approach described here as indirect communication are adopted by leaders as rhetorical devices intended, not to emancipate communication partner(s), but to project a charismatic image and entrench a particular standpoint (Den Hartog \& Verburg, 1997). Morrell (2006) illustrates how leaders, such as Winston Churchill, use aphorisms, in a particular sequence and setting, as rhetorical methods to frame a particular situation and create a sense of direction and shared purpose. At times of crises such communication technique may be considered necessary, but under normal circumstances its desirability may be challenged as an instance of the undesirable poverty of Buber's I-It relationship.

\section{Leadership and Dialogue: Concluding Thoughts}

There is an inherent danger in much of the leadership literature that leadership relations are viewed in more or less entirely instrumental ways: the leader interacts so that certain organisational aims can be achieved. This would equate with Buber's second interpretation of dialogue, as described above, that is, technical dialogue: the objective transmission of information. Instances, of this can be found, for example, in the notion of communicating the vision (Bryman, 1993; Kotter, 1996), which involves the transmission and clarification of information rather than constituting an interpersonal exchange. Some of the literature takes a different perspective and argues that the leader role can be a significant element for individuals to make sense of their situation and actions (e.g. Weick 2001). However, existential communication and, in particular, the notion of dialogue in relation to leadership goes beyond this. It does not present a superficial (albeit humanistic) view of relations but highlights potentialities.

Much is made of 'meaningful' relationships within the leadership literature (for example, Bass, 1995; Balfour et al, 1996) and leadership and meaning (Smircich and Morgan, 1982). Buber argues, as would other existential thinkers:

"We do not find meaning lying in things nor do we put it into things, but between us and things it can happen.” (2002: 42)

He notes specifically that in any 'factory or office' there is an immanent creative potential for and of dialogue.

"You can ask with a laugh: can the leader of a great technical undertaking practice the responsibility of dialogue? He (sic) can. For he practices it when he makes present to himself in its concreteness so far as he can, quantum satis, the business which he leads. He practices it when he experiences it, instead of as a structure of mechanical centres of force and their organic servants ... (but when an individual) steps really as an individual into the circle of vision and ... he is aware of him without strain not as a number with a human mask but as a person” (2002: 44)

Greenleaf's (1996) concept of servant leadership has the potential to be important here to the extent that it requires an attention to individual relationships such that the individual is recognised as unique and with particular needs and understandings which an aggregated view of 'followers' cannot accommodate. 
The above exposition of existential thinking and its application to leadership relations, we hope, provokes further thoughts on the potential for leadership and leadership communication. An existential approach allows for, indeed demands, the acceptance of potential - of possibility - in communication. Thus communication as dialogue is seen as a creative process, allowing the development of potential of all those involved in leader relations and as such it moves beyond the relative fixity of roles, implied in much leadership literature. In this way existential thinking may allow us to move beyond relatively recent concepts such as transformational leadership (Bass, 1995) where the leader creates transformations in the organisational context and in followers. This line of thinking develops that further to allow for transformation in all, including the leader.

\section{References}

Antonakis, J., Cianciolo A.T. and Sternberg, R.J. (eds.) (2004) The Nature of Leadership. Thousand Island, New Delhi, London: Sage.

Arnett, R.C. \& Arneson, P. (1999) Dialogic Civility in a Cynical Age: Community, Hope and Interpersonal Relationships, Albany NY, State University of New York Press.

Reference removed for reviewing purposes

Reference removed for reviewing purposes

Bass B.M. (1995) 'The Theory of Transformational Leadership Redux' The Leadership Quarterly, 6(4) Winter: 463-478

Bass, B.M. and Avolio, B.J. (1994) (eds.) Improving organizational effectiveness through transformational leadership, Thousand Oaks, Calif.; London, Sage.

Balfour, D.L. and Wechsler, B. (1996) 'Organizational Commitment: Antecedents and Outcomes in Public Organizations’, Public Productivity \& Management Review. 19(3): 256-277

Bennis, W. and Nanus, B. (1985) Leaders: The strategies of taking charge. New York: HarperCollins.

Bryman, A. (1993) Charisma and Leadership in Organisation. London, Sage.

Buber, M. (1958) I and Thou. Trans. R.G. Smith, Edinburgh, T \& T Clark.

Buber, M. (1998) The Knowledge of Man: Selected Essays, Amherst NY, Humanity Books.

Buber, M. (2002) Between Man and Man. London and New York. Routledge 
Cissna, K.N. \& Anderson, R. (2002) Moments of Meeting: Buber, Rogers and the Potential for Public Dialogue, Albany NY, State University of New York Press.

Collinson, D. (2005) ‘Questions of Distance’, Leadership, 1(2): 235-250.

Conger, J. A. and Kanungo, R.N. (1998) Charismatic Leadership in Organizations. Thousand Islands Ca., Sage.

Crossley, N. (1996) Intersubjectivity: The Fabric of Social Becoming, London, Sage.

Cunliffe, A.L. (2002) 'Social Poetics as Management Enquiry: A Dialogical Approach’ Journal of Management Inquiry 11(2):128-146.

Den Hartog, D.N. \& Verburg, R.M. (1997) 'Charisma and Rhetoric: The Communicative Techniques of International Business Leaders’, Leadership Quarterly, 8(4): 355-391

Federman, M. (2004). What is the Meaning of the Medium is the Message? Retrieved $20^{\text {th }}$ September 2007 from http://individual.utoronto.ca/markfederman/MeaningTheMediumistheMessage.pdf.

Fisher, B.A. (1974) Small Group Decisions Making: Communication and the Group Process. New York: McGraw-Hill.

Gordon, R. 'Martin Buber' in H.Gordon (ed) Dictionary of Existentialism, London, Fitzroy Dearborn, 58-63.

Graen, G.B. and Uhl-Bien, M. (1995) 'Relationship-based approach to leadership: development of leader-member exchange theory (LMX) over 25 years: Applying a multi-level, multi-domain perspective’ Leadership Quarterly, 6 219-247.

Greenleaf, R.K. (1996) On Becoming a Servant Leader: The Private Writings of Robert K. Greenleaf. Jossey-Bass Wiley.

Grieder, A. (1999) 'Truth’ in H.Gordon (ed) Dictionary of Existentialism, London, Fitzroy Dearborn: 472-6.

Gronn, P. (2000) 'Distributed Properties: a new architecture for leadership’ Education Management and Administration, 28(3): 317-338.

Heidegger, M. (1962) Being and Time. Trans. J. Macqurrie \& E. Robinson, Oxford, Blackwell.

Jaspers, K. (1954) Way to Wisdom. Trans. R. Manheim, New Haven CT, Yale University Press.

Jaspers, K. (1961) The Future of Mankind. Trans E.B. Ashton, Chicago IL, Chicago University Press. 
Jaspers, K. (1969/1971) Philosophy 3 vols. Trans E.B. Ashton, Chicago IL, Chicago University Press.

Jaspers, K. (1997) Reason and Existenz. Trans. W. Earle, Milwaukee WI, Marquette University Press.

Kakabadse, A. (1991) The Wealth Creators: Top People, Top Teams and Executive Best Practice. London Kogan Page.

Kierkegarrd, S. (1949) Either/Or: A Fragment of Life - Volumes 1 and 2. Translated by Walter Lowrie, Princeton, Princeton University Press.

Kierkegaard, S. (1992) Concluding Unscientific Postscript to Philosophical Fragments Volume 1.Trans H.V. and E.H. Hong, Princeton NJ, Princeton University Press.

Kotter, J.P. (1996) Leading Change Boston Mass. Harvard Business School Press.

Kouzes, J.M. and Posner, B.Z. (1987) The leadership challenge: How to get extraordinary things done in organizations. San Francisco; Jossey Bass.

Reference removed for reviewing purposes

Reference removed for reviewing purposes

Linstead, S. (1993). 'Deconstruction in the study of organizations'. In Hassard, J. and Parker, M. (Eds), Postmodernism and Organizations. Sage: London.

Littlejohn, S.W. \& Foss, K.A. (2005) Theories of Human Communication, $8^{\text {th }}$ Edition, Belmont CA, Wadsworth.

Macguire, S., McKelvey, B. Mirabeau, L. and Otzas, N. (2006) Complexity Science and Organizational Studies' In S.Clegg, C. Hardy, T.B. Lawrence, and W.R. Nord The Sage Handbook of Organization Studies ( $2^{\text {nd }}$ ed.) London: Sage. 165-214

McKelvey, B. (2002) 'Postmodernism vs. Truth in Management Theory’ in E. Locke (ed.) Post: Modernism \& Management: Pros, Cons, and Alternatives.

Amsterdam, NL: Elsevier.

Morrell, K. (2006) 'Aphorisms and Leaders’ Rhetoric: A New Analytical Approach', Leadership, 2(3): 367-382.

Pivcevic, E. (1970) Husserl and Phenomenology, London, Hutchinson.

Polt, R. (1999) Heidegger: An Introduction, London, UCL Press.

Rigby, D.K. (2001) Management Tools 2001 Forum. European Foundation for Management Development, December, 24-26. 
Salamun, K. (1999a) 'Existenz' in H.Gordon (ed) Dictionary of Existentialism, London, Fitzroy Dearborn: 150-1.

Salamun, K. (1999b) 'Relation’ in H.Gordon (ed) Dictionary of Existentialism, London, Fitzroy Dearborn: 397-400.

Sartre, J-P. (1996) Being and Nothingness. Trans. H. Barnes, London, Routledge.

Sokolowski, R. (2000) Introduction to Phenomenology, Cambridge, Cambridge University Press.

Smircich, L. \& Morgan, G. (1982) 'Leadership: the management of meaning.' Journal of Applied Behavioural Science, 18(3): 257-73

Smith, R.G. (1958) 'Preface’ to M. Buber, I and Thou. Trans. R.G. Smith, Edinburgh, T \& T Clark.

Stogdill, R.M. (1974) The Handbook of leadership: a survey of theory and practice. New York: Free Press.

The Leadership Trust (2002) Senior Management Attitude Survey. Ross-on-Wye. The Leadership Trust.

Watzlawick, P., Beavin, J. \& Jackson, D., (1967), Pragmatics of Human

Communication, W. W. Norton: New York.

Weick, K. (2001) Making Sense Of the Organization. Blackwell

Weston, M, (1994) Kierkegaard and Modern Continental Philosophy: An Introduction, London, Routledge.

Watson Wyatt (2006/7) Debunking the Myths of Employee Engagement. Watson Wyatt Worldwide (accessed January 2008 and available from:

http://www.watsonwyatt.com/research/resrender.asp?id=2006-US-0039\&page=1 